INVESTIGACIONES

de HISTORIA ECONÓMICA

2005, primavera, número 2. Pp. 145 a 178

\title{
Los empresarios y el Estado en torno a las intervenciones del régimen de Franco: la regulación de la inversión industrial (1938-1963)
}

\section{The role of enterprises and State in Franco's regime policies: the regulation of industrial investment (1938-1963)}

\author{
LUIS EDUARDO PIRES JIMÉNEZ \\ Universidad Rey Juan Carlos
}

\begin{abstract}
RESUMEN
Este artículo estudia una de las principales regulaciones industriales del franquismo: un sistema de autorización previa por el que las industrias necesitaban el permiso del Estado para abrir y realizar modificaciones en sus establecimientos. La interpretación tradicional sugería que esta política fue utilizada por los industriales establecidos para protegerse de la

competencia de los nuevos entrantes. Sin embargo, el análisis de la aplicación práctica de esta regulación, a través de los expedientes originales conservados en el Archivo General de la Administración y las resoluciones publicadas en el Boletín Oficial del Estado, permite matizar esta interpretación. Aunque en algunos casos los empresarios capturaron a los funcionarios del Estado, en otros fue el Estado el que impuso sus intereses. El marco dictatorial explica esta interacción entre los empresarios establecidos y el Estado, cuyos intereses estuvieron en conflicto permanente

alrededor de la aplicación práctica de la regulación de la inversión industrial.
\end{abstract}

PALABRAS CLAVE: Regulación, Política Industrial, Franquismo

Códigos JEL: H11, K23, L50, N44

\section{ABSTRACT}

This article discusses one of the most important economic policies of Franco dictatorship: A compulsory authorization that enterprises had to obtain from the Government as a previous step to open or modify their establishments. The traditional interpretation suggests that this regulation was used by the established industrials to protect themselves from new entering competitors. However, this idea is tinged with the analysis of the practical development of this policy, through the revision of the original files in the General Administration Archive, and the resolutions published in the Official Gazette. Sometimes the regulator was captured by the regulated established industrials, but sometimes the State's interests predominated. Finally, this interaction between the established industrials and the State about the regulation of the industrial investment is explained as a consequence of the institutional context of Franco's dictatorship.

KEY WORDS: Regulation, Industrial Policy, Franco regime

JEL Codes: H11, K23, L50, N44 


\section{Introducción ${ }^{1}$}

$\mathrm{U}$ no de los asuntos más debatidos en Economía es la elección entre regulación y libre mercado. Son muy conocidos los argumentos de los economistas favorables a la regulación, basados en que el gobierno debe intentar corregir, tanto los "fallos del mercado" derivados de la asignación ineficiente de los recursos, como la no maximización del bienestar social de dicha asignación. Frente a esta idea, otros autores se han replanteado el proceso regulador, aprovechando las aportaciones de las teorías de la elección pública y la búsqueda de rentas. Según estos economistas, la regulación se puede ver como una elección por parte de los oferentes (el Estado) y los demandantes (individuos, empresas, grupos) que compiten en un determinado marco político. Por un lado, se abre la posibilidad de que determinados agentes o grupos realicen una actividad de búsqueda de rentas del Estado mediante la demanda de regulación. Por otro, el marco político y legal de un país hace que, dentro del Estado, distintos agentes y grupos compitan entre sí para conseguir determinados objetivos (más poder, más presupuesto, beneficios económicos o morales). Y un instrumento que utilizan para obtenerlos es ofrecer regulación.

Este artículo investiga una de las políticas de intervención más intensas y representativas del régimen de Franco: la regulación de las inversiones industriales mediante la obligación a todas las empresas del país de obtener un permiso gubernamental previo para poder abrir o modificar sus establecimientos ${ }^{2}$. Entre los aspectos más interesantes de este estudio encontramos que esta intervención se desarrolló en una dictadura, mientras que las teorías de la regulación suelen referirse a entornos democráticos. Así ocurre, por ejemplo, con las investigaciones que consideran que los grupos compactos y mejor organizados se benefician de la regulación (en mayor medida que los grupos menos organizados), y que los políticos reguladores tienden a mantener una distribución políticamente óptima de la renta entre estos grupos, aunque también son sensibles a la pérdida de bienestar social asociada a la regulación ${ }^{3}$. Este argumento sirve de base para la denominada "hipótesis de la captura" que, aplicada a la intervención aquí estudiada, afirma que los empresarios ya establecidos, debido a que están mejor organizados y son un grupo más compacto que el de los nuevos entrantes o competidores, son capaces de apro-

1 Agradezco los comentarios de Mikel Buesa, Pedro Fraile, Antonio Gómez Mendoza, Santiago López, José Luis Ramos, Joan Ramón Rosés, Elena San Román y los tres evaluadores anónimos de la revista.

2 Algunos autores denominan a esta regulación "condicionamiento industrial", expresión plenamente aceptada en Portugal, donde también se aplicó esta misma intervención durante la dictadura de Salazar (19261974), pero que en España apenas es utilizada. Ver Pires (1999), (2002) y (2003).

$3 \quad$ Stigler (1971), Peltzman (1976), Becker (1983). 
vechar la regulación para, mediante la denegación de las peticiones de nuevas industrias, evitar su competencia. El Estado, por su parte, a pesar de buscar inicialmente otros objetivos teóricos al introducir la regulación, al final es capturado por esos grupos empresariales.

La literatura que ha analizado la regulación de la inversión industrial en España ${ }^{4}$, defiende la captura en los siguientes términos: el Estado, inicialmente y sin contar con los empresarios privados, impuso esta regulación, con la que intentó afrontar determinados problemas que se le presentaban (una economía de guerra, la regularización de las empresas tras el cese de los combates, o la escasez de divisas y de materias primas); sin embargo, estos problemas coyunturales no justifican que la regulación se mantuviera sin apenas cambios durante toda la dictadura, por lo que la única explicación de su permanencia está en que los empresarios privados, generalmente a través de los Sindicatos Nacionales, capturaron a los burócratas franquistas y utilizaron la regulación para defenderse de la competencia de nuevos entrantes.

El principal objetivo de nuestra investigación es completar y matizar tal interpretación, a partir del estudio de las fuentes primarias de esta regulación. Así, aunque algunos empresarios lograron capturar al Estado, en numerosas ocasiones las autoridades impusieron sus propios intereses en contra de los empresarios privados. En realidad, se estableció una interacción entre los intereses de los empresarios y los del Estado: la captura tuvo más probabilidad de producirse en aquellos sectores que no interferían con los objetivos de los burócratas franquistas, bien porque no utilizaban materias primas o divisas, cuya escasez les preocupó especialmente, bien porque no competían con el otro gran instrumento de intervención pública del período, el Instituto Nacional de Industria. El hecho de que la regulación se aplicara en un entorno dictatorial explica por qué la captura no se produjo de la forma como predice la teoría (y como apuntan los estudios previos de esta regulación). Así, se introdujo en circunstancias excepcionales (Guerra Civil), se mantuvo en vigor sin apenas cambios durante más de cuarenta años, y fue controlada por un pequeño número de funcionarios que consiguieron centralizar la decisión final de autorizar o denegar las peticiones de los empresarios privados, sin ninguna garantía ni control legal y logrando evitar el contrapeso que la propia legislación otorgaba a otros organismo del Estado, como los Sindicatos Nacionales. Esto hizo que las instancias reguladores y el procedimiento regulador escaparan a los mecanismos de un Estado democrático y produjeran una captura diferente a lo indicado en la teoría, con un mayor peso de la influencia individual y la discrecionalidad.

4 Desde los propios burócratas encargados de aplicar esta regulación, los ingenieros industriales Borrel (1943) y (1946), y Pozuelo (1955), hasta estudios más recientes como Buesa (1984) y Miranda (2003). 
Este artículo analiza el período 1938-1963, ya que en este último año se estableció un cambio legal (al que luego me referiré) que modificó ligeramente esta regulación, introduciendo una nueva política de establecimiento de tamaños mínimos para las empresas ${ }^{5}$. El presente artículo se estructura de la siguiente forma. El segundo epígrafe explica en qué consistió esta regulación industrial y describe su evolución legal. Posteriormente, los siguientes apartados analizan los dos agentes que intervinieron: desde el lado de la oferta de la regulación (el Estado) y de su demanda (los empresarios). El quinto epígrafe comprueba cómo se desarrolló la práctica de la regulación mediante un análisis estadístico de los expedientes originales. El sexto apartado son las conclusiones.

\section{Definición y desarrollo legal de la regulación de la inversión indus- trial en España}

La política industrial del franquismo se apoyó en tres leyes promulgadas durante los primeros años de la dictadura: la ley de Protección de las Nuevas Industrias de Interés Nacional (24/10/1939), la ley de Ordenación y Defensa de la Industria Nacional (24/11/1939) y la ley de Creación del Instituto Nacional de Industria (25/9/1941). La segunda de estas leyes incluía numerosas reglamentaciones que regulaban intensamente las industrias privadas, siendo la más importante la establecida en su artículo 4 (apartado a): "no podrán instalarse nuevas industrias, trasladar ni ampliar las existentes sin la resolución favorable del Ministerio de Industria y Comercio, quien fijará los trámites y normas a seguir, según las necesidades nacionales".

Durante la dictadura de Primo de Rivera (1926-1930) se había aplicado, por primera vez, una regulación similar a un número significativo de sectores ${ }^{6}$, con una Real Orden (4/11/1926) que, para desarrollar la intervención, creó el Comité Regulador de la Producción Industrial, precedente del futuro Ministerio de Industria. Aunque en los escasos cuatro años que estuvo en vigor la regulación apenas tuvo tiempo de desarrollarse, constituyó un precedente muy importante para su reinstauración durante el franquismo. Efectivamente, tras su derogación durante la II República (1931-1936), las autoridades industriales de los primeros gobiernos de Franco volvieron a implantar inmediatamente esta regulación industrial, bajo el impulso decisivo de Juan Antonio Suanzes, primer ministro de Industria en 1938. Es interesante destacar que esta regulación se empezó a aplicar en 1938 (Decretos 20/8/1938 y 8/9/1939), antes de la

Buesa y Pires (2002) estudian detenidamente la regulación en este período del franquismo tardío. Existen precedentes en la Restauración, en 1907, pero sólo en los sectores algodonero y azucarero. Ver Pires (1999), p. 145, y (2003), p. 16. 
entrada en vigor de la Ley de Ordenación y Defensa de la Industria Nacional $(24 / 11 / 1939)$. Esto demuestra que, desde el primer momento, antes incluso de terminada la Guerra Civil, existió una clara voluntad intervencionista de las autoridades franquistas en los procesos de inversión de la industria privada, a pesar de que en el preámbulo del primer decreto (el de 1938) se indicaba que se trataba de una disposición transitoria, propia de la situación de guerra. Esta voluntad, como veremos a continuación, permaneció durante todo el franquismo.

La regulación de la inversión industrial tuvo las siguientes características: 1) estableció un sistema de autorización previa, por el que las industrias necesitaban un permiso gubernamental para poder abrir o realizar modificaciones en sus instalaciones; 2) el permiso era necesario para cada uno de los establecimientos de una firma o empresa industrial, y se concedía sólo para una operación concreta en un momento determinado (apertura, ampliación, traslado, cambio de maquinaria, etc.), siendo necesario un nuevo permiso para posteriores operaciones; 3 ) las autoridades denegaban o autorizaban las solicitudes de los industriales, no en función de unas reglas previas, claras, e iguales para todos, sino basándose en los criterios que en cada momento estimaban convenientes (discrecionalidad); y 4) la regulación afectaba a todos o (desde 1963) a la mayoría de los sectores industriales del país. Una regulación que cumpla con estas características sólo se ha producido en España durante las dictaduras de Miguel Primo de Rivera (19261930) y Francisco Franco (1938-1975), y fuera de España, en Portugal durante la dictadura de Salazar y, con menor intensidad, en la Italia de Mussolini y en la Alemania nazi.

Tras el Plan de Estabilización de 1959, se aprobaron diversas disposiciones legislativas que liberalizaron la regulación de la inversión industrial (que culminaron con el Decreto 26/1/1963). La entrada en 1962 de un nuevo ministro de Industria, Gregorio López Bravo, con una mentalidad más liberal, junto con la retirada política de los últimos representantes de la mentalidad industrializadora autárquica, liderados por Suanzes, promovió este cambio. La nueva regulación permitía que las autoridades del Ministerio de Industria excluyeran algunos sectores industriales de la obligación de pedir permiso para abrir o modificar sus establecimientos. A su vez, introdujo una nueva política consistente en exigir en algunos sectores que los nuevos establecimientos cumpliesen unas condiciones técnicas y de tamaños mínimos, a fin de corregir el problema del pequeño tamaño de las industrias en España. Aunque el Decreto de 1963 excluyó de la obligación de necesitar autorización administrativa previa para sus operaciones de inversión a muchos sectores industriales, en 1966 se endureció la legislación volviendo a estar la mayoría de los sectores industriales obligados a pedir permiso para abrir o ampliar sus establecimientos ${ }^{7}$. En definitiva, y tal como ocurrió con la mayoría de las intervenciones franquistas, pocos años después de la liberalización promovida por el Plan de Estabiliza- 
ción de 1959, las autoridades volvieron a introducir nuevas regulaciones (o a recuperar las ya existentes) que se volvían a aplicar tan intensamente como antes de $1959^{8}$.

La regulación de la inversión industrial en España se derogó definitivamente en 1980, tras la llegada de la democracia. Esto muestra una estrecha relación entre esta regulación y las dictaduras, ya que la llegada de regímenes democráticos, en 1930 y a finales de los años 1970 en España, y también en 1974 en Portugal ${ }^{9}$ y en 1945 en Italia y Alemania (los otros países donde se aplicó) supuso su completa derogación.

En resumen, el régimen de Franco tuvo, desde el primer momento (antes incluso de terminar la Guerra Civil), una clara voluntad intervencionista en los procesos de inversión de la industria privada, voluntad que permaneció durante todo el franquismo a pesar de los tímidos y breves intentos liberalizadores de principios de los años sesenta.

\section{La oferta de regulación: el Estado}

La intensidad con la que se aplica una regulación que otorga capacidad de prohibición a la Administración se mide, en una primera aproximación, comprobando cuántas peticiones se prohibían ${ }^{10}$. La media de denegaciones durante todo este período fue del 26 por $100^{11}$. Los primeros años, a principios de los cuarenta, fueron los de mayor intensidad denegatoria, llegando hasta el 51 por 100 en 1941. La intensidad de la regulación comenzó a disminuir en los primeros años cincuenta, manteniéndose de media en el 15 por 100 de expedientes denegados. A partir de 1960, el porcentaje de denegaciones volvió a disminuir, coincidiendo con el período de liberalización económica general a raíz del Plan de Estabilización de 1959.

El motivo más inmediato para denegar un expediente era que el sector industrial al que afectase tuviera un exceso de producción con las fábricas ya instaladas, por lo que el regulador centró su atención en las dos operaciones que implicaban un aumento de la capacidad productiva: la instalación de un nuevo establecimiento industrial y la ampliación de la capacidad de producción de un establecimiento ya

\section{González (1979), Serrano y Pardos (2002).}

Ver Pires (1999), cap. 6 y (2002) para el caso portugués.

Este ejercicio se ha realizado en Pires (1999), cap. 4 y (2003), utilizando las resoluciones publicadas en el BOE y los expedientes conservados en el AGA y en diversos Boletines Provinciales (ver Fuentes).

11 Esta media se ha calculado a partir de los expedientes conservados en el AGA: Pires (1999), p. 173 y (2003), p. 40. La media de denegación de los expedientes de las empresas más grandes, cuya resolución se publicaba en el BOE, fue inferior, del 18 por 100 (Apéndice). Estos porcentajes contrastan con la media de denegaciones durante la dictadura de Primo de Rivera (1926-1929), que fue del 3 por 100: Pires (1999), p. 171 y (2003), p. 39. 


\section{GRÁFICO 1}

NUEVAS INDUSTRIAS Y AMPLIACIONES EN LA REGULACIÓN DE LA INVERSIÓN INDUSTRIAL, 1940-1962 (líneas de tendencia logarítmica)

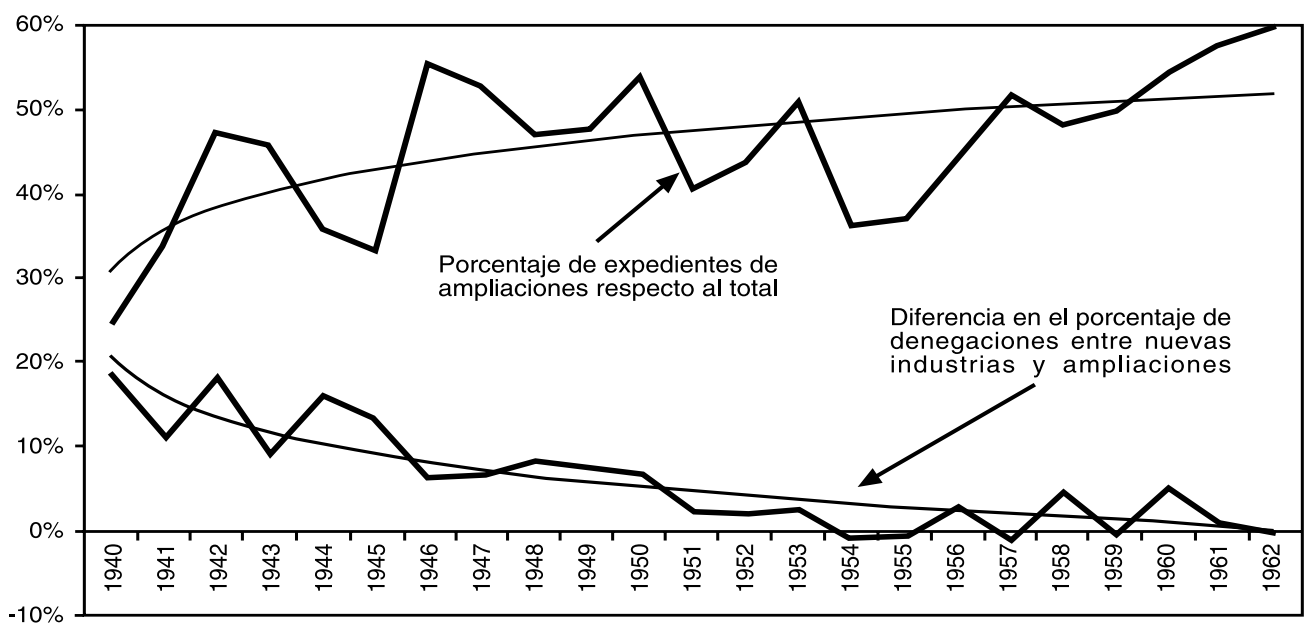

Fuente: BOE, años 1940-1962.

existente $^{12}$. Además, la diferencia de trato a las peticiones de nuevas industrias y ampliaciones permite comprobar la existencia de captura, al distinguir de forma aproximada a los industriales establecidos (que solicitan ampliaciones), frente a los entrantes (que solicitan nuevas industrias). La captura se produce si los primeros consiguen que no se autoricen nuevas industrias, a la vez que se reparten las ampliaciones entre ellos. Los datos globales muestran que, frente a una media de denegaciones del 18 por 100, en las nuevas industrias subió al 23 por 100, mientras que para las ampliaciones se quedó en un 9 por 100. El Gráfico 1 profundiza en esta cuestión a través de dos datos. El primero (línea superior), muestra cuántos expedientes eran de nuevas industrias y cuántos de ampliaciones. Como cabía esperar, al principio de la regulación tras la Guerra Civil hubo muchas más peticiones para abrir nuevas instalaciones, pero con el tiempo las solicitudes de ampliaciones superaron a las de nuevas industrias. El segundo dato (línea inferior) expone la evolución en el porcentaje de denegaciones entre ambas operaciones. Las nuevas industrias se denegaban más que las ampliaciones, ya que la diferencia media (como se acaba de indicar) fue del 14 por 100, pero esta diferencia disminuyó a lo largo del tiempo, coincidiendo con el relajamiento de la intensidad reguladora hasta el final del período. 
CUADRO 1

EVOLUCIÓN DE LOS TRES PRINCIPALES MOTIVOS DE DENEGACIÓN EN LA REGULACIÓN DE LA INVERSIÓN INDUSTRIAL (porcentajes)

\begin{tabular}{lccc} 
Períodos & 1. Industrias suficientes & 2. Escasez de materias primas & 3. Escasez de divisas \\
\hline $\mathbf{1 9 4 0 - 6 2}$ & 23 & 58 & 19 \\
$\mathbf{1 9 4 1 - 5 1}$ & 19 & 75 & 5 \\
$\mathbf{1 9 5 2 - 6 2}$ & 31 & 17 & 52 \\
$\mathbf{1 9 4 0 - 4 5}$ & 18 & 76 & 5 \\
$\mathbf{1 9 4 6 - 5 1}$ & 33 & 58 & 8 \\
$\mathbf{1 9 5 2 - 5 6}$ & 53 & 29 & 18 \\
$\mathbf{1 9 5 7 - 6 2}$ & 26 & 14 & 60 \\
\hline
\end{tabular}

Fuente: BOE, años 1940-1962.

El exceso de capacidad productiva y la posible existencia de captura no fueron, sin embargo, los únicos aspectos que influyeron en esta regulación. Las autoridades solían indicar en los expedientes denegados las causas de dicha denegación y, en la mayoría de las ocasiones (un 80 por 100), emplearon tres argumentos. El primero es el que denominaron "industria suficiente", cuando entendían que en un sector industrial había un exceso de producción ya cubierto por las empresas existentes. Los otros dos argumentos fueron la "escasez de materias primas", cuando la industria tenía difícil obtener los inputs necesarios para su producción, y la "escasez de divisas", en este caso la industria peticionaria necesitaba importar muchos inputs del exterior. En el Cuadro 1 se expone la evolución temporal de estos tres motivos. El argumento de la industria suficiente presenta una evolución más homogénea durante todo el período, debido a la estabilidad que esta legislación mantuvo en su transcurso. Sin embargo, los otros dos motivos (materias primas y divisas) fueron más coyunturales.

La escasez de materias primas fue un problema de los años cuarenta que provocó fuertes enfrentamientos entre el Ministerio de Comercio e Industria (MIC) y los Sindicatos Nacionales (se analizan más adelante). Este problema aparece como uno de los factores fundamentales en la explicación del alto grado de denegaciones en esos años. Una vez que se iba resolviendo, y coincidiendo con el incremento de la producción industrial en los años cincuenta ${ }^{13}$, el porcentaje general de denegaciones se redujo sensiblemente. El problema de las divisas escasas fue más intenso en los años cincuenta,

13 Carreras (1990). 
y se puede asociar con la política de sustitución de importaciones. Así, la interpretación de aquellos autores ${ }^{14}$ que sostienen que esta política sólo se intentó llevar a cabo en los años cincuenta y no en los cuarenta, encaja con los datos aquí presentados:

\begin{abstract}
"Se ha hablado de la orientación hacia la sustitución de importaciones como propia de aquellos años [los cuarenta]. El planteamiento industrial era seguramente menos ambicioso. Se trataba de resolver exclusivamente determinados estrangulamientos en materias primas para industrias y productos nacionales y no se planteaba la producción de bienes "exóticos"15.
\end{abstract}

La política industrial general del régimen franquista también influyó en esta regulación. Así, el franquismo buscó una industrialización a toda costa, centrando sus esfuerzos en las industrias de bienes de equipo y descuidando las industrias de bienes de consumo ${ }^{16}$. Esta estrategia implicaría, en relación con la regulación de la inversión industrial, un mayor porcentaje de denegaciones en las industrias de bienes de consumo que en las de bienes de equipo. Y así ocurrió; sectores como el de alimentos, bebidas, textiles, o calzado y prendas de vestir, presentan unos porcentajes de denegaciones superiores a las eléctricas, químicas, metalurgia o maquinaria (ver Apéndice).

También influyó en esta regulación el Instituto Nacional de Industria. Según la interpretación tradicional ${ }^{17}$, el INI trató de desarrollar determinados sectores estratégicos para la industrialización de España, compensando la falta de iniciativa privada y las limitaciones del sistema financiero en el apoyo a esas industrias. Como recoge el Cuadro 2, el porcentaje de denegaciones en estos sectores fue muy bajo, sobre todo en los que más énfasis pusieron los directivos del INI, como minería, metalurgia o electricidad.

Sin embargo, numerosos estudios han criticado esta interpretación, mostrando cómo el INI perjudicó a empresas privadas ya establecidas o que intentaban establecerse en esos sectores ${ }^{18}$. Para ello utilizó fondos públicos, privilegios y regulaciones a su favor, entre las que destacó la regulación sobre la inversión industrial, mediante la denegación de nuevas industrias de empresarios privados que competían con las empresas del INI.

\footnotetext{
Donges (1976).

Clavera y otros (1973), I, p. 263.

Carreras (1990), González (1990), Morellá (1992), Catalán (1995).

Martín Aceña y Comín (1991).

Por ejemplo, ver Fraile (1992) para la siderurgia, San Román (1995) para los automóviles, San Román y Sudriá (1999) para los hidrocarburos sintéticos, Gómez Mendoza (2000), pp. 69-84, para la industria eléctrica, o Valdaliso (1997) para la construcción naval. Para una defensa general de esta idea, ver Gómez Mendoza y San Román (1997).
} 


\section{CUADRO 2}

LOS SECTORES ESTRATÉGICOS DEL INI Y LA REGULACIÓN DE LA INVERSIÓN INDUSTRIAL

\section{Sector industrial}

\section{Denegaciones}

(\%)
Año y grado de participación (\%) en las empresas del sector

\section{MINERÍA}

Investigación minera

Extracción de carbón

Plomo y cinc

Potasas

Fosfatos

$\begin{array}{ll}- & 1942(100 \%) \\ 0 & 1943(16,7 \%), 1944(20 \%) \text { y } 1961(83 \%) \\ 0 & 1945(28,1 \%) \\ - & 1952(52,5 \%) \text { y } 1960(99 \%) \\ - & 1962\end{array}$

\section{METALURGIA}

Hierro y acero

6,5

$1949(17,8 \%)$ y $1950(100 \%)$

Aluminio

9,1

$1943(75 \%)$ y $1960(52 \%)$

\section{ELECTRICIDAD}

Tendidos eléctricos

Producción y distribución de gas

\section{HIDROCARBUROS}

Derivados del petróleo y carbón

Refinerías de petróleo

4,5

$1942(100 \%)$ y $1949(52 \%)$

40

\section{INDUSTRIA TRANSFORMADORA}

Construcciones navales

$0 \quad 1947(100 \%)$ y $1952(94 \%)$

Aeronaves

Vehículos automóviles
1944, 1946, 1951, 1954 y 1961

$1952(99,9 \%)$

$01952(99,9 \%)$
$1943(33,3 \%), 1944(33,3 \%)$ y $1954(33,3 \%)$ $1946(52,1 \%)$ y $1950(51 \%)$

\section{MAQUINARIA Y BIENES DE EQUIPO}

Motores de avión

Herramientas

Maquinaria agrícola

Rodamientos

Armas militares

Equipos ferroviarios

Óptica y precisión

Material eléctrico

$\begin{array}{rl}10 & 1951(84,2 \%) \\ 0 & 1944(70 \%) \\ 21,1 & 1946(18,2 \%) \\ 15,1 & 1946(75 \%) \\ 0 & 1959(100 \%) \\ 0 & 1956(41 \%) \\ - & 1951(100 \%) \\ 5,6 & 1942(30 \%)\end{array}$


Denegaciones

(\%)
Año y grado de participación (\%) en las empresas del sector

\section{QUÍMICAS}

Abonos

Celulosas

Fibras artificiales

Productos aromáticos

Resinas

aromático
iciales

\section{ALIMENTOS}

Frío industrial

Conservas de frutas y legumbres

Pesca

31,7

$1949(55 \%), 1951(51 \%)$ y $1956(65,7 \%)$

$1955(100 \%)$

$28,6 \quad 1944(40,1 \%)$

$801950(33,3 \%)$

$0 \quad 1949(60 \%)$

\section{TEXTIL (Málaga) (*)}

0

1960

- $\quad 1947(6,7 \%)$

$\left({ }^{*}\right)$ Empresa textil por la ausencia de estas empresas en Málaga.

Fuente: Martín Aceña y Comín (1991) y Apéndice.

Para concluir el análisis de la oferta de la regulación, es necesario tener en cuenta la existencia de varios agentes encargados de su aplicación. Cada expediente se iniciaba con una petición dirigida al MIC por parte del empresario. Posteriormente, una serie de organismos corporativos (principalmente, los Sindicatos), además de otros industriales de la competencia, expresaban su opinión acerca de esa petición. Estos informes no eran vinculantes, sino consultivos para el MIC, que finalmente resolvía. Dentro del MIC, la aplicación directa de esta regulación corrió a cargo de la Dirección General de Industria (DGI), que contaba para ello con una sección en Madrid sólo dedicada a esta regulación, denominada "Nuevas Industrias", y con las Delegaciones Provinciales de Industria.

El estudio de los expedientes originales y otros documentos conservados en el Archivo General de la Administración, muestra cómo los funcionarios de la DGI centralizaron la decisión final de autorizar o denegar un expediente, excluyendo a cualquier otro organismo del Estado. Como en la sección de "Nuevas Industrias" sólo había un número reducido de funcionarios (cuatro en 1947) ${ }^{19}$, era materialmente

19 Según he podido comprobar con unos partes de trabajo semanales de estos funcionarios de la sección de Nuevas Industrias conservados en el AGA, sección “Industria”, caja 7.125. Ver Pires (1999), p. 215 y (2003), pp. 72-74. 
imposible que estos pocos burócratas pudieran resolver los miles de expedientes anuales originados por la regulación. Por eso las autoridades establecieron, a través de la normativa legal, mecanismos que facilitaron este control centralizado de la regulación. Así, se dividieron las industrias para que aquellos expedientes más relacionados con los objetivos estratégicos del Estado (por ejemplo, los que utilizaban materias primas o divisas escasas), fueran tratados directamente por los funcionarios de la DGI, mientras que el resto (industrias pequeñas o que no tenían problemas de escasez de inputs) se resolvieran en las Delegaciones Provinciales de Industria ${ }^{20}$. Los funcionarios de estas delegaciones provinciales se encargaban de recoger la documentación de todos los expedientes, enviaban a la Dirección Central los expedientes más importantes (los de empresas grandes o que utilizaban inputs escasos) y resolvían el resto. El control de la DGI sobre estos funcionarios locales fue muy grande, ya que sus resoluciones se podían recurrir ante la DGI y, además, la propia DGI elaboró unas fichas con criterios para cada sector industrial que servían de orientación a las resoluciones que hacían los funcionarios de las provincias. En definitiva, un número muy reducido de burócratas en Madrid centralizó las resoluciones de los expedientes de esta regulación.

Además del MIC y del industrial peticionario, la legislación contemplaba la participación de otros organismos que podían informar y asesorar a los funcionarios de la DGI. La mayoría de estos asesoramientos provinieron de los Sindicatos Nacionales o de Servicios que pertenecían al ámbito de la organización sindical. La progresiva pérdida de influencia política de los Sindicatos durante el franquismo ${ }^{21}$, sobre todo en el ámbito económico, también se notó en la regulación de la inversión industrial. Por un lado, los Sindicatos sólo tenían una función asesora ${ }^{22}$, mientras que la decisión final sobre autorizar o denegar el expediente correspondía en exclusiva a los funcionarios de la DGI. El Cuadro 3 compara los informes de los Sindicatos con la resolución final adoptada por la DGI: aunque los Sindicatos se mostraron muy activos en esta regulación (el 80 por 100 de estos expedientes tuvieron informes sindicales), en muchos casos la DGI adoptó la resolución contraria a lo sugerido por los Sindicatos, principalmente informes negativos que al final se autorizaban (NS en el cuadro).

20 Estos cambios se introdujeron con el Decreto 8/9/1939, que derogaba el primer decreto de esta regulación (de 20/8/1938). La experiencia acumulada por los burócratas de la DGI en esos meses y su voluntad de centralizar la decisión final aparecen como la principal explicación de este cambio legislativo, toda vez que el nuevo decreto apenas introdujo cambios relevantes en otros aspectos de la regulación.

21 Payne (1961).

22 Además, su informe no era obligatorio para resolver el expediente (excepto cuando la industria peticionaria empleaba materias primas sometidas a cupos de distribución por algún organismo oficial). 


\section{CUADRO 3}

RELACIÓN ENTRE LOS INFORMES DE LOS SINDICATOS Y LAS RESOLUCIONES DE LA DGI (industrias textil y química, en porcentaje)

\begin{tabular}{lrrrrr}
\hline Textil & 1943 & 1947 & 1952 & 1959 & Total \\
\hline SS & 7 & 20 & 29 & 20 & 20 \\
NN & 16 & 47 & 9 & 22 & 22 \\
SN & 1 & 1 & 46 & 4 & 2 \\
NS & 14 & 32 & 13 & 82 & 36 \\
OS & 45 & 0 & 2 & 3 & 16 \\
ON & 16 & 1952 & 1959 & 5 \\
\hline Química & 1943 & 1947 & 40 & 51 & Total \\
\hline SS & 9 & 35 & 15 & 7 & 35 \\
NN & 33 & 30 & 38 & 1 & 20 \\
SN & 0 & 20 & 7 & 34 & 25 \\
NS & 6 & 8 & 0 & 7 & 14 \\
OS & 38 & 5 & 0 & 5 \\
ON & 15 & & & & \\
\hline
\end{tabular}

Primera letra: $\mathrm{S}=$ Sindicato informa favorablemente, $\mathrm{N}=$ informa negativamente, $0=$ no informa.

Segunda letra: S = DGI autoriza, N = DGI deniega.

Fuente: AGA, ver Apéndice.

Por otro lado, la revisión de los expedientes originales conservados en el AGA muestra un intenso enfrentamiento entre los funcionarios de la DGI y los Sindicatos en torno al sistema de cupos. El reparto de estos cupos de materias primas escasas, al tener un precio de tasa por debajo del precio de mercado, podía estimular artificialmente la hipertrofia de instalaciones fabriles que sólo buscaban especular con esos $\operatorname{cupos}^{23}$. La necesaria coordinación entre los dos organismos que controlaban dos regulaciones diferentes, pero relacionadas entre sí, derivó en un intenso enfrentamiento ${ }^{24}$. La reacción de la DGI fue, primero, reafirmar su plena y única facultad 
de autorizar o denegar expedientes, al margen del informe sindical, aunque la nueva industria o ampliación necesitara utilizar materias primas sometidas a cupo; y en segundo lugar, ante las protestas de industriales autorizados por el ministerio a los que posteriormente los Sindicatos no concedían los cupos para poder operar, la DGI se desentendió en un principio de ellos, indicando en sus resoluciones que la autorización no daba derecho para reclamar esos cupos, pero finalmente consiguió, incluso, quitarle competencias a los Sindicatos en este terreno a través de la Orden 25-41946:

\begin{abstract}
“Autorizada la instalación o ampliación de una industria por este Ministerio, en la forma que se expresa en el número anterior, los Organismos distribuidores de cupos de materias primas vendrán obligados a facilitar los que correspondan aunque hubiesen informado en sentido desfavorable las oportunas peticiones de instalación o ampliación de dichas industrias" (cursiva mía). BOE, 131, 11-5-1946, p. 4.014.
\end{abstract}

En definitiva, los funcionarios de la DGI se mostraron muy celosos en sus cometidos y no permitieron que nadie, a pesar de la labor asesora que obligaba la legislación, les disputara su capacidad de autorizar o denegar expedientes. No obstante, los Sindicatos Nacionales sí tuvieron en determinados casos una labor bastante activa en la defensa de los intereses de los empresarios ya establecidos. De eso se ocupa el siguiente epígrafe.

\title{
4. La demanda de regulación: el empresario y sus empresas
}

La regulación de la inversión industrial influyó intensamente en todos los elementos de la actividad empresarial. La denegación de los proyectos empresariales para abrir nuevos establecimientos industriales, ampliar su capacidad productiva o trasladarla a otra provincia, influyó negativamente en la creación de empresas ${ }^{25}$. Pero, además de la puesta en funcionamiento de una industria, había muchas otras operaciones que estaban también bajo el control directo de los burócratas del Ministerio de Industria: el tipo de maquinaria a utilizar (nueva o usada), la tecnología a emplear, el número de obreros, etc. En este caso, las autoridades no actuaban a través de la denegación de los expedientes, sino mediante la concesión de autorizaciones "condicionadas" a que se cambiaran algunas características del proyecto original presentado por el peticionario. 
Todo lo anterior aumentó considerablemente los costes de las empresas: los burocráticos (gastos de trámites y tasas); el tiempo que tardaba la solicitud en ser resuelta por las autoridades, una media de 7 meses ${ }^{26}$; y los costes asociados a la incertidumbre de una posible denegación de la solicitud. Estos problemas no fueron causados sólo por esta regulación industrial, ya que otras intervenciones estatales, como la necesidad de pedir permisos para obtener electricidad, materias primas, transporte, o inputs proporcionados por el resto de las industrias, dificultaban el posterior desarrollo de la función empresarial, originaban corruptelas y hacían que muchas empresas funcionaran al margen de la ley (es decir, que operaran sin el preceptivo permiso gubernamental). Todo lo anterior aumentó los costes fijos y variables de las empresas (los futuros aumentos de producción requerirían nuevas solicitudes), resultando una economía que se situaba muy por debajo de su frontera de posibilidades de producción.

En Pires (1999) y (2003) aparecen numerosos ejemplos de estas distorsiones en la función empresarial, de los que destaco tres. En el primero, la escasez de hojalata en los años cuarenta dificultó la actividad de las fábricas de conservas, lo que justificó numerosas denegaciones a estas industrias. Algunos empresarios reaccionaron proponiendo utilizar la madera como envase, lo que facilitó la autorización de esos proyectos; pero una empresa de conservas de tomates propuso envasar en vidrio, a lo que la DGI se negó afirmando que el envase de vidrio no era económico ${ }^{27}$. El funcionario de la DGI, que en el citado expediente no expone ningún argumento o cifra para sostener su afirmación, frustró una innovación empresarial que hoy en día está muy desarrollada, como es la presentación del tomate en envases de vidrio. Por tanto, las autoridades franquistas no sólo descuidaron el desarrollo tecnológico de la economía española ${ }^{28}$, sino que incluso lo desincentivaron en muchas ocasiones.

El segundo ejemplo es el de la preocupación del MIC porque las industrias utilizasen máquinas nuevas en lugar de maquinaria de segunda mano. Así, muchas denegaciones se basaban sólo en este aspecto, y la DGI instó a los ingenieros de las Delegaciones Provinciales a que vigilaran la compra de maquinaria usada por las nuevas industrias ${ }^{29}$. Las máquinas nuevas, evidentemente, tienen una función de coste variable menor que las viejas. Pero esto no significa que sólo sea rentable producir con máquinas nuevas. Existen otros muchos factores que pueden hacer que la utilización de máquinas viejas sea también rentable: la diferencia entre los dos costes variables medios, el precio de mercado, la amortización de los costes de capital

Pires (1999), p. 222 y (2003), pp. 79-81.

Expediente n ${ }^{\circ} 10.563$, AGA, sección "Industrias", caja 5.545.

López y Valdaliso (1997).

Estos ingenieros veían un indicio de la existencia de maquinaria usada cuando comprobaban que el capital declarado en la solicitud era inferior al precio de las máquinas nuevas en el mercado. 
de la máquina vieja, o las expectativas sobre los precios futuros del mercado. El criterio de impedir sistemáticamente a las nuevas industrias que comprasen máquinas usadas fue muy rígido y dificultó que los empresarios aprovechasen oportunidades de mercado.

El tercer ejemplo es el de las salas cinematográficas. Aunque la mayoría de las actuaciones de las autoridades en esta regulación se caracterizaron por la ausencia de reglas claras, lo que provocaba una gran discrecionalidad, en esta ocasión sí que se fijó un criterio objetivo: el aforo de todos los cines de una localidad no podía exceder del 20 por 100 de su población. Sin embargo, esto provocó, a su vez, nuevas distorsiones, ya que suponía homogeneizar la demanda de cine en toda España, perjudicando a aquellas poblaciones donde esta demanda fuera mayor, incentivando el monopolio en poblaciones muy pequeñas, e impidiendo la competencia y la expansión de las posibilidades de consumo de los demandantes de cine.

Por último, la regulación de la inversión industrial afectó de forma negativa al tamaño de los establecimientos industriales. Desde el punto de vista legal, las empresas muy pequeñas tenían que cumplir menos requisitos para solicitar el permiso $^{30}$. Pero, además, la revisión de los expedientes originales conservados en el AGA confirma cómo muchas industrias pequeñas, aunque tuvieran problemas (porque utilizaran divisas o materias escasas, o estuvieran en un sector muy saturado), eran autorizadas con el argumento de que su pequeño tamaño no afectaría al resto del sector. Por último, la dificultad de cambiar de negocio ante la incertidumbre de conseguir una nueva autorización aumentó la resistencia de los pequeños empresarios a abandonar sus proyectos empresariales una vez en funcionamiento, aunque fueran de dudosa viabilidad. En definitiva, esta regulación incentivó artificialmente la aparición y el mantenimiento de industrias muy pequeñas. Precisamente, uno de los principales objetivos de las reformas legislativas introducidas en la regulación de la inversión industrial en 1963 fue corregir este problema mediante el establecimiento de tamaños mínimos para las nuevas industrias, aunque en parte fuera un problema causado por las propias regulaciones de las autoridades franquistas ${ }^{31}$.

A todo lo anterior hay que añadir que las resoluciones tenían una calidad técnica muy baja, ya que simplemente indicaban si una solicitud era autorizada o denegada, pero sin justificar casi nunca la decisión con datos; también, que la regulación tuvo una ausencia destacada de garantías legales para los industriales, que

\footnotetext{
30 Concretamente, aquellas empresas que no importaran maquinaria, ni utilizaran materias primas escasas, y cuyo capital fuera inferior a 50.000 pesetas o tuvieran menos de 25 obreros, eran siempre autorizadas; a esto se unió el trato de favor a las industrias "artesanales".

31 Buesa y Pires (2002).
} 
no podían recurrir a los Tribunales de Justicia, e incluso la posibilidad de recurrir ante instancias superiores del MIC fue recortada mediante algunas disposiciones ${ }^{32}$. Todo ello aumentó la discrecionalidad de la Administración y la indefensión de los industriales.

La instauración de la regulación de la inversión industrial en agosto de 1938 no fue provocada por la presión empresarial. España estaba en plena Guerra Civil y el político que la introdujo, Juan Antonio Suanzes, que había llegado a su cargo apenas siete meses antes y no se había dedicado hasta entonces a la política, pudo desarrollar libremente sus ideas industriales y mostró una gran animadversión contra el "gran capital", por lo que no fue fácilmente "capturable" por los empresarios privados en esos primeros años ${ }^{33}$. La implantación de esta regulación industrial en 1938, por tanto, no se debió a una demanda activa por parte de los empresarios, los cuales tampoco pudieron modificarla legalmente, ya que los cambios legales de principios de los años 1960 sólo trataron de solucionar el problema del "minifundismo industrial" que preocupaba especialmente a las autoridades franquistas, pero que no reflejaron ningún interés empresarial ${ }^{34}$.

Lo único que pudieron hacer los empresarios fue intentar capturar a los reguladores mediante la utilización de esta intervención como una barrera de entrada frente a los nuevos competidores. Algunos autores defienden, en términos generales, que la captura del Estado por los intereses privados, a través de las agencias reguladoras, fue completa ${ }^{35}$. Esta es precisamente la tesis que han adoptado muchos estudios de la regulación de la inversión industrial ${ }^{36}$. Incluso en las propias publicaciones del Ministerio de Industria se apunta la posibilidad de que esta intervención se utilizara como un instrumento anticompetencia ${ }^{37}$. El hecho de que la decisión de autorizar o denegar los expedientes estuviera centralizada en unos pocos funcionarios de la Dirección General de Industria refuerza la probabilidad de esa captura.

En este artículo, por el contrario, y sin negar la existencia de algunas estrategias de búsqueda de rentas, se defiende que la actitud empresarial en esta regulación fue menos activa. Esta hipótesis está en línea con diferentes estudios sobre los empresarios españoles, tanto generales ${ }^{38}$ como sectoriales $^{39}$.

Como las órdenes 3/2 / 1941 y 26/1/1942. Ver Pires (1999), cap. 4 y (2003), pp. 19-23.

Ballestero (1993), San Román (1999).

Buesa y Pires (2002).

Fraile (1999).

Borrel (1943) y (1946), Pozuelo (1955), Buesa (1984), Miranda (2003).

Ver en Fuentes MIC (1947), p. 30.

Cabrera y Del Rey (1996).

Gómez Mendoza y San Román (1997), Pons (1999), Valdaliso (2002), Torres (2003b). 
Así, en Pires (1999) y (2003) se describen algunos casos concretos de captura por parte de los grupos empresariales mediante esta regulación. Por ejemplo, la Dirección General de Industria suspendió todas las autorizaciones de nuevas industrias en algunos sectores. En varios casos esta situación fue provocada por la actuación de los empresarios, sobre todo a través de los Sindicatos encargados de defender sus intereses. El caso más claro fue el del Sindicato Nacional de la Alimentación que consiguió ciertos resultados, como la fijación de coeficientes para la adjudicación de materias primas en $1944^{40}$, o la prohibición por la DGI de todas las autorizaciones de industrias de pastas para sopa en $1955^{41}$, de las industrias cárnicas ${ }^{42}$, de las de jabón ${ }^{43}$, de las que utilizaran azúcar ${ }^{44}$, o de las de la piel $^{45}$. Y aunque se sale del período estudiado, también hubo captura después de 1963, mediante el establecimiento en algunos sectores de unos tamaños mínimos tan grandes que ninguna nueva empresa podía cumplirlos ${ }^{46}$.

Sin embargo, la captura no fue una práctica generalizada, ya que en muchas ocasiones los Sindicatos no pudieron - aunque lo intentaron- utilizar esta regulación para beneficiar a los empresarios que representaban. Así ocurrió, por ejemplo, con las cerveceras en Valencia, donde una empresa ("El Águila") se salió del acuerdo propiciado por el Sindicato para establecer una fábrica común en Valencia, y creó la suya propia ${ }^{47}$. Otro ejemplo muestra cómo, desde la Dirección General de Industria, se trataron de evitar algunas situaciones de posible corrupción ${ }^{48}$. Un tercer caso es el del sector de los cementos, uno de los más claros ejemplos de comportamiento oligopólico $^{49}$. El porcentaje de denegaciones en este sector fue muy bajo ${ }^{50}$, aunque la mayoría de las peticiones eran de ampliaciones y no de nuevas industrias. La expli-

Circular n 227 de la Dirección General de Industrias, conservada en el AGA, sección "Industrias", caja 7.180 .

41 Circular no 665 de la Dirección General de Industrias, conservada en el AGA, sección "Industrias", caja 7.180.

42 Ya no se utilizó una circular interna, como antes, sino una Orden publicada el 13/12/1943.

43 Orden $13 / 1 / 1943$.

44 Orden $17 / 6 / 1943$

45 Orden $10 / 1 / 1947$

46 Buesa y Pires (2002).

47 García Ruiz y Laguna (1999).

48 Expediente $n^{\circ} 36.793$, AGA, sección "Industrias", caja 6.210, donde un empresario textil denuncia que se ha denegado su petición porque existe una clara corrupción y connivencia entre los Sindicatos y los funcionarios del ministerio que defienden a los industriales establecidos. Su carta es muy visceral, afirmando que la decisión para abrir un nuevo establecimiento está "en manos de unos pocos señores", y que no tiene confianza en el recurso pero que al menos le sirve para descargar su frustración. El Director General de Industria, Luis Pombo Polanco, contestó personalmente al industrial, y a pesar de lamentar la "acritud" del recurso, autorizó finalmente la apertura de su establecimiento.

49 Gómez Mendoza (1987), Rosado (1997).

$50 \quad$ Entre el 8 y el 10 por 100, ver Apéndice. 
cación de esta paradoja es que los empresarios de cementos, sobre todo los de cemento portland, eran un grupo muy poderoso que tenía la capacidad de capturar al Estado para protegerse de la competencia, pero entre los instrumentos que utilizaron para esta protección no estuvo la regulación de la inversión industrial, sino otros como el control, a través de otras regulaciones estatales, de la propiedad de las minas necesarias para el negocio. Para este grupo, por tanto, la regulación de la inversión industrial no servía para sus intereses, más bien era un estorbo, pues la barrera de entrada se producía antes de la petición de la solicitud (al adquirir las minas). Por eso la mayoría de peticiones eran ampliaciones, su porcentaje de denegaciones fue muy bajo, y la mayoría de esas denegaciones se produjo en la provincia de Cádiz en los años 1954-1956, lo que fue, seguramente, un reflejo de la lucha por el control oligopolístico en esa provincia (se trataba de un oligopolio espacial).

La revisión de los expedientes originales ha mostrado algunas prácticas que pretendían evitar que la regulación actuase como barrera de entrada, como comprar e instalar maquinaria antes de solicitar la autorización administrativa, o abrir una industria con un capital inferior a 50.000 pesetas — cuya autorización era más fácil de conseguir - , para luego ampliarla hasta el capital en un principio deseado — una solicitud de ampliación era más fácil que una de nueva industria-. Las autoridades poco pudieron hacer frente a estas prácticas, y preferían poner una pequeña multa antes que clausurar una fábrica ya en funcionamiento. Las características legales de esta regulación también dificultaron la posibilidad de utilizarla como una barrera de entrada. Al contrario de lo que ocurría en otras regulaciones ${ }^{51}$, la autorización no daba lugar a ningún derecho dentro de la propia regulación. Además, aunque el permiso para abrir una nueva industria permitía optar a la solicitud de otros permisos (materias primas, electricidad, licencias de importación), los propios funcionarios de la DGI solían avisar en los expedientes de que su autorización no daba ningún derecho en estas otras regulaciones ${ }^{52}$.

En conclusión, aunque se han encontrado ejemplos de captura, los empresarios establecidos no pudieron utilizar de forma generalizada la regulación de la inversión industrial como una barrera de entrada para dificultar la competencia. Entre las causas que dificultaron la captura, además de las indicadas en este apartado, está el importante grado de autonomía del Estado frente a los intereses empresariales que se apuntó en el epígrafe anterior. Por ello el siguiente apartado analizará conjuntamente el comportamiento de estos dos agentes.

51 Por ejemplo, en la obligación de pedir permiso para importar, tras un complejo proceso burocrático, "una vez aprobados los trámites de primera importación temporal, era posible reincidir en operaciones idénticas", Clavera y otros. (1973), I, p. 230.

52 Borrel (1943), p. 44, ofrece varios ejemplos; también expuestos en Pires (1999), pp. 258-259 y (2003), p. 97. 


\section{La práctica de la regulación}

En el desarrollo práctico de la regulación de la inversión industrial en España hubo dos agentes que trataron de imponer sus intereses, los empresarios y el Estado. A continuación, se valora la influencia de ambos en la aplicación práctica de esta regulación. Para ello, se han analizado estadísticamente los 4.471 expedientes publicados en el BOE durante los años 1940-1962 (ver Apéndice y Fuentes). La variable independiente es la autorización o denegación de un expediente, y las variables dependientes son el año de resolución, la región ${ }^{53}$, el sector industrial ${ }^{54}$, la utilización de materias primas escasas ${ }^{55}$, la propensión a exportar e importar ${ }^{56}$, la consideración del sector como estratégico por parte de las autoridades franquistas ${ }^{57}$, el tipo de operación (nueva industria o ampliación), y el grado de oligopolio del sector al que pertenecen $^{58}$. El objetivo es determinar la probabilidad que tenía un expediente de ser autorizado en función de esas variables. Para ello se ha utilizado un modelo logit de ecuaciones para datos de panel (General estimating equation logit). El modelo procede a eliminar, mediante iteraciones, la influencia de aquellas variables que pueden introducir distorsiones (heterocedasticidad) en el análisis de los resultados, dejando sólo aquellas variables relevantes para la explicación de la variable independiente. Los resultados son muy robustos y se ofrecen en el Cuadro 4.

Como se puede observar, las variables relevantes fueron cinco, y toman los valores esperados. Tres de ellas se asocian con los intereses del Estado: 1) la utilización de materias primas escasas, que reducía la probabilidad de ser autorizado; 2) el ahorro de divisas, que aumentaba dicha probabilidad; y 3) la pertenencia a un sector considerado estratégico por las autoridades franquistas, que también la aumentaba. Las otras dos se asocian a los intereses de los empresarios establecidos: 4) si se trataba de una operación de nueva industria, en vez de ampliación, se reducía la probabilidad de ser autorizado; y 5) pertenecer a un sector oligopolizado aumentaba dicha probabilidad.

53 Las provincias (el dato que aparece en el BOE) se han agrupado en función de la división administrativa actual de España por Comunidades Autónomas.

54 Siete grandes sectores: extractivo; alimentos, bebidas y tabaco; artículos de consumo (textil, madera, cueros, etc.); química; metálicas básicas; maquinaria; y diversas.

55 Sectores que alguna vez estuvieron intervenidos por los organismos que controlaban los cupos de materias primas (Sindicatos, Comisaría General de Abastecimientos y Transportes).

56 Porcentaje de exportaciones, menos porcentaje de importaciones respecto a la producción final de cada sector industrial, en función de la Tabla Input-Output del año 1958, para aproximar el ahorro (signo positivo) o el gasto (signo negativo) de divisas en cada sector.

57 Sectores estratégicos del INI según Martín Aceña y Comín (1991).

58 Cálculo efectuado por Buesa y Molero (1998) sobre los datos de empleo industrial por tamaños de empresa del Censo Industrial de 1958. 


\section{CUADRO 4}

ESTIMACIÓN DE LA PROBABILIDAD DE QUE UN EXPEDIENTE FUERA AUTORIZADO

\begin{tabular}{lcccccc}
\hline Autorizado & Coeficiente & $\begin{array}{c}\text { Error } \\
\text { estándar }\end{array}$ & $\mathbf{Z}$ & $\mathbf{P}>[\mathbf{z}]$ & $\begin{array}{c}\text { Intervalo de confianza } \\
\text { del 95\% }\end{array}$ \\
\hline 1. Materias primas & $-0,1948907$ & 0,0322974 & $-6,034$ & 0,000 & $-0,2581925$ & $-0,1315890$ \\
2. Divisas & 0,0094695 & 0,0043879 & 2,158 & 0,031 & 0,0008695 & 0,0180696 \\
3. Sectores estratégicos & 0,2848939 & 0,1564668 & 1,821 & 0,069 & $-0,0217755$ & 0,5915632 \\
4. Tipo de operación & $-0,4961691$ & 0,1054986 & $-4,703$ & 0,000 & $-0,7029426$ & $-0,2893955$ \\
5. Oligopolio & 0,0025273 & 0,0014532 & 1,739 & 0,082 & $-0,0003210$ & 0,0053755 \\
Constante & 1,4282330 & 0,2434302 & 5,867 & 0,000 & 0,9511182 & 1,9053470 \\
\hline
\end{tabular}

$N^{\circ}$ de observaciones: 4.471. Familia: binomial con una media de 194,39.

Correlación: intercambiable con un máximo de 552. Escala paramétrica: 1 . Probabilidad > chi²: 0 .

Pearson chi ${ }^{2}$ (4465): 6.257,28. Desviación: 4.104,84. Dispersión (Pearson): 1,401407. Dispersión: 0,9193378.

Fuente: ver texto.

El desarrollo de una regulación depende de cuatro factores: 1) si la agencia reguladora está a favor o en contra del mercado; 2) si el político tiene una actitud activa o pasiva; 3) si están mejor organizados los entrantes o, por el contrario, lo está el grupo que controla la industria; y 4) si la competición destruye, o no, las rentas industriales. Una agencia contraria al mercado, un político pasivo, un grupo de presión organizado, y una destrucción importante de las rentas industriales, provocan un aumento de la cartelización y de la probabilidad de que se dé la captura ${ }^{59}$. En la regulación de la inversión industrial en España, todos los supuestos anteriores se cumplieron excepto el de la pasividad de los políticos. Por ello, aunque hubo captura, también los intereses del Estado importaron. El hecho de que las cinco variables del modelo sean significativas refleja una interacción entre los empresarios establecidos y el Estado, cuyos intereses estuvieron en conflicto permanente en torno a la aplicación práctica de esta regulación. Por eso no se puede afirmar, ni que hubo captura de los empresarios, ni que el Estado impuso sin más sus intereses. En cada sector industrial se pudo dar una u otra opción. 


\section{CUADRO 5}

COMPORTAMIENTO ESTRATÉGICO EN LA REGULACIÓN SOBRE LA INVERSIÓN INDUSTRIAL

\begin{tabular}{|c|c|c|c|}
\hline \multicolumn{2}{|c|}{} & \multicolumn{2}{|c|}{$\begin{array}{r}\text { Porcentaje de denegaciones de nuevas } \\
\text { industrias menos ampliaciones }\end{array}$} \\
\cline { 2 - 4 } & \multicolumn{2}{|c|}{ ALTO } & BAJO \\
\hline \multirow{2}{*}{$\begin{array}{c}\text { Porcentaje de } \\
\text { denegaciones total }\end{array}$} & ALTO & 1 & 2 \\
\cline { 2 - 4 } & BAJO & 3 & 4 \\
\hline
\end{tabular}

El Cuadro 5 trata de describir esta interacción comparando el porcentaje de denegación total con el porcentaje que supone la diferencia de denegación entre las nuevas industrias y las ampliaciones en el total, siempre dentro de cada sector industrial.

Desde el punto de vista de los empresarios establecidos, las mejores situaciones son la 1 y la 3, debido a que se autorizan más las ampliaciones que las nuevas industrias. Si el sector al que pertenecen tiene problemas para crecer y expansionarse, la opción óptima es la 1, ya que se mantiene el statu quo denegando la mayoría de las peticiones. La opción 3 es aún mejor que la 1 para los industriales establecidos que, en este caso, se hallan en un sector en expansión, donde se autorizan muchos expedientes de ampliación a la vez que se deniegan peticiones de nuevas industrias, lo que les protege de la competencia de nuevos entrantes. Sin embargo, 3 no es un punto de equilibrio, al no ser los empresarios establecidos los únicos agentes que participan en este juego estratégico: hay que tomar también en consideración los intereses del Estado. Si uno de sus principales objetivos en su política económica fue industrializar el país mediante el aumento de la producción, al Estado sólo le interesaba incrementar las denegaciones en aquellos sectores que tenían problemas (principalmente de materias primas y de divisas) y así sus opciones preferidas son la 3 y la 4 , con un porcentaje bajo de denegaciones. Con este razonamiento, y combinando los intereses de ambos agentes, se esperaría que la mayoría de los sectores se situaran en el punto 3. Sin embargo, eso no fue lo que sucedió en la práctica, como se aprecia en el Cuadro 6, donde aparece la posición real en la que se situaron los diferentes sectores industriales en función de este comportamiento estratégico ${ }^{60}$.

60 El comportamiento estratégico se ha calculado viendo cómo se sitúa cada sector respecto a la media de denegaciones total (18,3 por 100) y a la media de la diferencia entre las denegaciones a las nuevas industrias y a las ampliaciones (13,7 por 100). Ver Apéndice. 


\section{CUADRO 6}

PRINCIPALES SECTORES EN CADA COMPORTAMIENTO ESTRATÉGICO

\begin{tabular}{|c|c|c|c|}
\hline 1 & & 3 & \\
\hline ALIMENTOS & Cerveza y malta & Volframio, estaño y titanio & Calzado de caucho \\
\hline Carnes & CALZADO & Conserva de pescados & Aceites y grasas \\
\hline Lácteos & CUERO & Azúcar & Productos Aromáticos \\
\hline Conservas frutas & QUÍMICA & Piensos & Detergentes \\
\hline Molinos de Harinas & Colas & Levadura & Adhesivos \\
\hline Productos Dietéticos & Insecticidas & Seda & Máquinas para agricultura \\
\hline Panaderías & Pinturas & Fibras artificiales & Máquinas para otras industrias \\
\hline Caramelos & Ceras y parafinas & Neumáticos de caucho & Electrónica y cine \\
\hline Chocolates & Jabones & 4 & \\
\hline Pastas sopa y purés & Refinerías & PROD. Y DISTRIB. DE GAS & Metales \\
\hline Café & Vidrio & EXTRACCIÓN DE CARBÓN & Plásticos \\
\hline BEBIDAS & Máquinas construcción & EXTR. MINER. METÁLICOS & Resinas \\
\hline Licores & Fotografía y óptica & EXTR. PIEDRA (Caolines) & Sales \\
\hline 2 & & EXTR. MINER. NO METÁLICOS & Productos Farmacéuticos \\
\hline Géneros de punto & Hierro y acero & Aceite de oliva & Coque \\
\hline Litografía & Aluminio & Margarinas & Aglomerados de carbón \\
\hline Abonos & Recipientes & Extractos y condimentos & Arcilla \\
\hline Explosivos & Máquinas para metales & Vinagre & Cemento (no aluminoso) \\
\hline DERIV. PETROLEO & Producción electricidad & Gaseosas & Metal. no férrea no aluminio \\
\hline Cerámica & Lámparas & TABACO & PROD. METÁLICOS \\
\hline Cemento aluminoso & Acumuladores y pilas & TEXTILES & Motores \\
\hline Otros cementos & Instrumentos música & $\begin{array}{l}\text { Prendas de vestir y confección } \\
\text { MADERA Y CORCHO } \\
\text { MUEBLES } \\
\text { PAPEL } \\
\text { GRAFICAS (no litografía) } \\
\text { QUIMICA } \\
\text { Ácidos } \\
\text { Alcoholes } \\
\text { Gases }\end{array}$ & $\begin{array}{l}\text { Máquinas manipular fluidos } \\
\text { Máquinas distr. electricidad } \\
\text { Maquinaria eléctrica vehículos } \\
\text { Electrodomésticos } \\
\text { Frío industrial } \\
\text { CONSTR. MAT. TRANSP. } \\
\text { Instrumentos científicos } \\
\text { Relojes } \\
\text { Juguetes } \\
\text { Artículos materias plásticas }\end{array}$ \\
\hline
\end{tabular}

Fuente: Cuadro 5 y Apéndice. 
Estos datos exigen un razonamiento que no se base en las acciones independientes de cada agente, sino en la interacción entre ellos. Así, si un sector industrial no estaba afectado por los problemas que preocupaban a las autoridades franquistas (divisas, materias primas), lo más probable es que fuera autorizado, y ante este alto porcentaje de autorizaciones, la captura se hizo muy complicada. Por ello, la opción 4 predomina sobre la 3 . Pero si un sector se enfrentaba a los problemas anteriores, la probabilidad de ser capturado aumentaba, lo que se refleja en que hay más sectores en 1 que en 2. Es decir, la actuación del Estado influyó en la actuación de los industriales establecidos, ya que si aumentaban las denegaciones en un sector, los empresarios podían aprovecharse de esa situación para erigir una barrera de entrada frente a los nuevos competidores.

Junto a las estrategias predominantes, 4 y 1, otros factores particulares explican por qué determinados sectores se situaron en los otros puntos. Así, los intereses del Instituto Nacional de Industria y la evolución de su competencia con los empresarios privados explica cómo la opción 3 se corresponde con un INI en formación que autoriza todos sus nuevos proyectos, y como muchos sectores donde el INI fracasó se sitúan en la opción 2. A su vez, un porcentaje bajo de denegaciones (opciones 3 y 4) no corresponde sólo a sectores donde existía una cierta competencia, sino que también puede incluir sectores que poseían otros mecanismos para evitarla, ya que la regulación de la inversión industrial no era el único mecanismo que con este fin poseían el Estado o los empresarios establecidos. Es el caso ya visto anteriormente de los cementos, que evitaban la competencia mediante el control de la propiedad de las minas, y lo mismo ocurrió en varios sectores controlados por el INI. El hecho de que fueran los mismos políticos, liderados por Suanzes, los que controlaron el INI y el MIC durante los años cuarenta y cincuenta, explica la subordinación de todos los mecanismos reguladores que tenían a su alcance (de los que la regulación de la inversión industrial sólo era uno de ellos) para conseguir sus objetivos de industrialización autárquica.

\section{Conclusión}

La regulación sobre la apertura y ampliación de establecimientos industriales fue la primera intervención industrial que introdujeron las autoridades franquistas, todavía en plena Guerra Civil, mostrando una inequívoca voluntad de controlar intensamente las actividades empresariales privadas. Este control, a pesar de una breve y tímida liberalización a principios de los años sesenta, continuó intensamente y sin apenas cambios hasta el final de la dictadura. Los empresarios privados pudieron utilizar esta regulación para dificultar la entrada de nuevos competidores, y así lo hicieron en algunos casos. Pero el análisis de los expedientes originales conservados 
en el AGA y de las resoluciones publicadas en el BOE, muestra que aquélla no fue una práctica generalizada, ya que el Estado, a través de los altos funcionarios del Ministerio de Industria, tuvo un importante grado de autonomía que le permitió imponer en muchas ocasiones sus intereses frente a los de los industriales privados. Estos intereses se enmarcan dentro de la política de industrialización franquista, y consistieron en dirigir el uso de materias primas y divisas escasas, controlar a las empresas privadas, y complementar los intereses estratégicos del INI.

El entorno dictatorial en el que se desarrolló esta regulación explica por qué los empresarios establecidos no capturaron de forma generalizada al Estado para utilizar esta regulación como una barrera de entrada. Su introducción en plena Guerra Civil sin contar con la opinión de los empresarios, su mantenimiento en vigor sin apenas cambios durante toda la dictadura, el férreo y centralizado control de todo el proceso regulador por un pequeño grupo de funcionarios del Ministerio de Industria, la falta de garantías legales y la eliminación efectiva de los contrapesos que la propia legislación otorgaba a otros organismo del Estado, como los Sindicatos Nacionales, provocaron que las instancias y el procedimiento regulador escaparan a los mecanismos de un Estado democrático, dando un mayor peso a la influencia individual y a la discrecionalidad frente a la captura generalizada de las organizaciones empresariales. En definitiva, esta regulación subordinó la libertad de industria a los intereses del Estado y de algunos grupos de empresarios establecidos, quienes trataron de aprovecharla para imponer sus intereses particulares.

\section{Fuentes}

Archivo General de la Administración ( $A G A$ )

Los expedientes originales tramitados por la Dirección General de Industria (DGI), incluyendo los recursos de los expedientes de las Delegaciones Provinciales de Industria, se conservan en la sección "Industrias" del AGA: cajas 5.281 a 6.948, expedientes numerados del 1 al 68.899 .

Otras cajas de la sección "Industrias" y de la sección "Sindicatos" conservan también numerosos documentos relacionados con esta regulación.

Boletín Oficial del Estado (BOE)

La Dirección General de Industrias publicó en el BOE, entre 1939 y 1962, la resolución de los 4.471 expedientes (incluidos en el Apéndice) de las empresas que necesitaban importar maquinaria o utilizar materias primas escasas, o cuyo capital superaba las 750.000 pesetas (Decreto 8/9/1939).

También el BOE recopiló, pero sólo hasta 1944, las resoluciones que tramitaban las delegaciones provinciales y que se publicaban en los Boletines Provinciales. 
Ministerio de Industria y Comercio (MIC), Dirección General de Industria

(1940): “Comisión reguladora de las industrias químicas", Madrid.

(1941): “Avance-resumen de la labor realizada desde octubre de 1939 a octubre de 1941 por aplicación del Decreto de 8-IX-39 que regula el establecimiento de nuevas industrias", Madrid.

(1942): “La política industrial en la nueva España. Síntesis gráfica presentada en la XX feria-muestrario internacional de Valencia y X de Barcelona", Madrid.

(1946): "Informe sobre el condicionamiento industrial", mimeografía conservada en el AGA, Sección "Industrias", caja n n $^{\circ} 181$.

(1947): "Memoria-resumen de las actividades desarrolladas por los servicios de industria durante el bienio 1945-1946", Madrid.

Ministerio de Industria y Comercio (MIC), Consejo de Industria

Memorias Anuales, años 1942 y 1953-63.

\section{Bibliografía}

BALLESTERO, Alfonso (1993): Juan Antonio Suanzes, 1891-1977. La política industrial de la posguerra, León, LID Editorial Empresarial.

BECKER, Gary S. (1983): "A theory of competition among pressure groups for political influence", Quarterly Journal of Economics, 98, agosto, pp. 371-400.

BORREL Y MACIÁ, José (1943): Instalación y modificación de industrias (comentarios al Decreto de 8 de septiembre de 1939 y disposiciones complementarias, a base, principalmente, de Resoluciones de la Dirección General de Industria), Barcelona, Bosch.

-(1946): El intervencionismo del Estado en las actividades económicas, su extensión y límites, Barcelona, Bosch.

BUESA, Mikel (1984): “Las restricciones a la libertad de industria en la política industrial española (1938-1963)”, Información Comercial Española, 606, pp. 107-121.

BUESA, Mikel, y MOLERO José (1998): Economía industrial de España: organización, tecnología e internalización, Madrid, Cívitas.

BUESA, Mikel, y PIRES Luis E. (2002): “Intervencionismo estatal durante el franquismo tardío: la regulación de la inversión industrial en España (1963-1980)", Revista de Historia Industrial, 21, primer semestre, pp. 159-198.

CABRERA, Mercedes, y DEL REY Fernando (1996): “Los intereses económicos organizados en España. Un siglo en la historia del asociacionismo empresarial", en COMÍN, Francisco, y MARTÍN ACEÑA, Pablo (eds.), La empresa en la historia de España, Madrid, Civitas, pp. 441-456.

CARRERAS, Albert (1990): Industrialización española: estudios de historia cuantitativa, Madrid, Espasa Calpe. 
CATALÁN, Jordi (1995): La economía española y la segunda guerra mundial, Barcelona, Ariel. CLAVERA, Joan, ESTEBAN, Joan M., MONÉS, M. Antònia, MONSERRAT, Antoni, y ROS HOMBRAVELLA, Jacinto (1973): Capitalismo español: de la autarquía a la estabilización (1939-1959), Madrid, Cuadernos para el diálogo.

DONGES, Juergen B. (1976): La industrialización en España. Politicas, logros, perspectivas, Barcelona, Oikos-tau.

FRAILE, Pedro (1992): “Interés público y captura del Estado: la empresa pública siderúrgica en España, 1941-1981”, Fundación Empresa Pública, Programa de Historia Económica, Documento de Trabajo 9.203, Madrid.

-(1999): "Spain: Industrial Policy under Authoritarian Politics", en FOREMANPECK, James, y FEDERICO, Giovanni (eds.), European Industrial Policy. The Twentieth Century Experience, Nueva York, Oxford University Press, pp. 233-267.

GARCÍA RUIZ, José L., y LAGUNA, Constanza (1999): Cervezas Mahou, 1890-1998. Un siglo de tradición e innovación, Madrid, LID.

GÓMEZ MENDOZA, Antonio (1987): “Oligopoly and economic efficiency: portland cement in Spain (1899-1935)", Rivista di Storia Economica, 4, pp. 76-95.

-(2000) (ed.): De mitos y Milagros. El Instituto Nacional de Autarquía (1941-1963), Barcelona, Fundación Duques de Soria-Universitat de Barcelona.

GÓMEZ MENDOZA, Antonio, y SAN ROMÁN, Elena (1997): “Competition betwen private and public enterprise in Spain, 1939-1959: an alternative view", Business and Economic History, 26, 2, Invierno, pp. 1-12.

GONZÁLEZ, Manuel J. (1979): La economía politica del franquismo (1940-1970), Madrid, Tecnos.

-(1990): "La autarquía bajo el régimen del general Franco: una visión desde la teoría de los derechos de propiedad", Información Comercial Española, 676-677, pp. 19-31.

LAFFONT, Jean-Jacques, y TIROLE, Jean (1993): A theory of incentives in procurement and regulation, Massachusetts Institute of Technology.

LÓPEZ, Santiago, y VALDALISO, Jesús M. (1997): ¿Qué inventen ellos? Tecnología, empresa y cambio económico en la España contemporánea, Madrid, Alianza.

MARTÍN ACEÑA, Pablo, y COMÍN, Francisco (1991): INI, 50 años de industrialización en España, Madrid, Espasa Calpe.

MIRANDA, José A. (1998): La industria del calzado en España (1860-1959). La formación de una industria moderna y los efectos del intervencionismo estatal, Alicante, Generalitat Valenciana e Instituto de Cultura Juan Gil-Albert.

-(2003): "El fracaso de la industrialización autárquica”, en BARCIELA, Carlos (ed.), Autarquía y mercado negro, Barcelona, Crítica, pp. 95-121.

MORELLÁ, Enric (1992): “El producto industrial de posguerra: una revisión (Índices sectoriales, 1940-1958)", Revista de Historia Económica, Año X, 3, pp. 125-143.

PAYNE, Stanley G. (1961): Falange: a history of spanish fascism, Stanford, Stanford University Press. 
PELTZMAN, Sam (1976): “Toward a more general theory of regulation”, The Journal of Law and Economics, Vol. XIX, 2, pp. 211-248.

PIRES, Luis E. (1999): La regulación económica en las dictaduras: el condicionamiento indus-trial en España y Portugal durante el siglo XX, Tesis Doctoral, Universidad Complutense de Madrid (publicado en formato electrónico).

-(2002): “A política industrial de Portugal e Espanha durante o século 20. Divergências com Europa", Revista de História Económica e Social, 3, 2ª serie, primer semestre, pp. 15-67.

-(2003): Regulación industrial y atraso económico en la dictadura de Franco, Madrid, Dykinson, Servicio de Publicaciones de la Universidad Rey Juan Carlos.

PONS, M ${ }^{a}$ Angeles (1999): “Capture or agreement? Why Spanish banking was regulated under the Franco regime, 1939-75", Financial History Review, 6, pp. 25-46.

POZUELO Y BARNUEVO, José Enrique (1955): La industrialización...¿necesaria?, Madrid, Espasa Calpe.

ROSADO, Ana I. (1997), La organización industrial del sector cementero español (19421996), Tesis Doctoral, Universidad Complutense de Madrid.

SAN ROMÁN, Elena (1995): “El nacimiento de la SEAT: autarquía e intervención del INI", Revista de Historia Industrial, 7, pp. 141-165.

-(1999): Ejército e industria: el nacimiento del INI, Barcelona, Crítica.

SAN ROMÁN, Elena, y SUDRIÁ, Carles (1999): “Autarquía e ingenierismo: la Empresa Nacional 'Calvo Sotelo' y la producción de lubricantes sintéticos", en CARRERAS, Albert, PASCUAL, Pere, REHER, David S., y SUDRIÁ, Carles (eds.), Doctor Jordi Nadal. La industrialización y el desarrollo económico de España, Barcelona, Universitat de Barcelona.

SERRANO SANZ, José M., y PARDOS, Eva (2002): “Los años de crecimiento del franquismo (1959-1979)", en COMÍN, Francisco, HERNÁNDEZ, Mauro, y LLOPIS, Enrique (eds.), Historia Económica de España. Siglos X-XX, Barcelona, Crítica, pp. 369-396.

STIGLER, George J. (1971): "The theory of economic regulation", The Bell Journal of Economics and Management Science, 2, 1, pp. 3-21.

TORRES, Eugenio (2003a): “La empresa en la autarquía 1939-1959. Iniciativa pública versus iniciativa privada", en BARCIELA, Carlos (ed.), Autarquía y mercado negro, Barcelona, Crítica, pp. 169-216.

-(2003b): "Comportamientos empresariales en una economía intervenida: España, 1936-1957", en SÁNCHEZ, Glicerio, y TASCÓN Julio (eds.), Los empresarios de Franco. Política y economía en España, 1936-1957, Barcelona, Crítica, pp. 199-224.

VALDALISO, Jesús M. (1997): “Programas navales y desarrollo económico: la Empresa Nacional 'Elcano' de la Marina Mercante y el sueño industrializador de Suanzes (1942-1963)", Revista de Historia Industrial, 12, pp. 147-177.

-(2002): "Grupos empresariales, marco institucional y desarrollo económico en España en el siglo XX: los negocios de la familia Aznar (c. 1937-c. 1983)", Revista de Historia Económica, 3, pp. 577-624. 


\section{APÉNDICE}

CLASIFICACIÓN, POR SECTORES INDUSTRIALES, DE LOS EXPEDIENTES DE LA REGULACIÓN DE LA INVERSIÓN INDUSTRIAL, 1940-1962

\begin{tabular}{|c|c|c|c|c|c|c|}
\hline (1) & (2) & (3) & (4) & (5) & (6) & (7) \\
\hline 512 & PRODUCCIÓN Y DISTRIB. DE GAS & 29 & 0 & 48 & 0 & 4 \\
\hline 14 & EXTRACCIÓN DE CARBÓN & 7 & 0 & 43 & 0 & 4 \\
\hline 12 & EXTRAC. MINERALES METÁLICOS & 92 & 11 & 10 & 0 & 4 \\
\hline 121 & HIERRO & 4 & 0 & 25 & 0 & 4 \\
\hline 122 & NO FERREOS & 87 & 11 & 9 & -1 & 4 \\
\hline 1221 & Mercurio & 1 & 0 & 0 & 0 & 4 \\
\hline 1222 & Piritas & 12 & 0 & 33 & 0 & 4 \\
\hline $1223 x$ & Cobre & 5 & 0 & 0 & 0 & 4 \\
\hline $1223 x$ & Plomo y cinc & 23 & 0 & 4 & 0 & 4 \\
\hline 1224 & Volframio, estaño y titanio & 26 & 38 & 8 & -11 & 2 \\
\hline 1225 & Metales preciosos (oro) & 2 & 0 & 0 & 0 & 4 \\
\hline 1229 & Otros & 9 & 0 & 0 & 0 & 4 \\
\hline 143 & PIEDRA, ARCILLA Y ARENA & 10 & 0 & 10 & 0 & 4 \\
\hline 19 & EXTRAC. MINERALES NO METÁLICOS & 19 & 0 & 47 & 0 & 4 \\
\hline 1911 & Sal común & 14 & 0 & 57 & 0 & 4 \\
\hline 199 & OTROS & 5 & 0 & 20 & 0 & 4 \\
\hline 20 & PRODUCTOS ALIMENTICIOS & 521 & 63 & 22 & 33 & 1 \\
\hline 201 & CARNES & 17 & 47 & 24 & 62 & 1 \\
\hline 202 & LÁCTEOS & 38 & 45 & 21 & 43 & 1 \\
\hline 203 & CONSERVA FRUTAS Y LEGUMBRES & 41 & 32 & 25 & 30 & 1 \\
\hline 204 & CONSERVA DE PESCADOS & 22 & 41 & 30 & 2 & 2 \\
\hline 205 & MOLINOS & 79 & 70 & 26 & 27 & 1 \\
\hline 2051 & Harinas & 59 & 69 & 32 & 39 & 1 \\
\hline 2056 & Dietéticos & 5 & 100 & 0 & 100 & 1 \\
\hline $205 x$ & Otros & 15 & 60 & 17 & -50 & 2 \\
\hline
\end{tabular}




\begin{tabular}{|c|c|c|c|c|c|c|}
\hline (1) & (2) & (3) & (4) & (5) & (6) & (7) \\
\hline 206 & PANADERÍAS & 71 & 79 & 6 & 61 & 1 \\
\hline 207 & AZUCAR & 24 & 38 & 36 & -2 & 2 \\
\hline 208 & CACAO, CHOCOLATE, CONFITUR & 83 & 73 & 36 & 17 & 1 \\
\hline $208 x$ & Caramelos & 34 & 76 & 38 & 16 & 1 \\
\hline $208 x$ & Chocolates & 49 & 71 & 34 & 18 & 1 \\
\hline 209 & DIVERSAS & 146 & 67 & 18 & 47 & 1 \\
\hline 2091 & Aceite de oliva & 1 & 0 & 100 & 0 & 4 \\
\hline 2092 & Margarinas & 1 & 0 & 0 & 0 & 4 \\
\hline 2093 & Extractos y condimentos & 4 & 0 & 75 & 0 & 4 \\
\hline 2094 & Pastas para sopa y purés & 43 & 86 & 10 & 39 & 1 \\
\hline 2095 & Café & 17 & 82 & 0 & 82 & 1 \\
\hline 2096 & Piensos & 36 & 89 & 12 & -10 & 2 \\
\hline 2098 & Levadura & 36 & 89 & 33 & 0 & 2 \\
\hline 2099 & Otras & 40 & 38 & 32 & 38 & 1 \\
\hline 21 & BEBIDAS & 116 & 25 & 31 & 28 & 1 \\
\hline 211 & LICORES & 25 & 64 & 12 & 35 & 1 \\
\hline 212 & VINAGRE & 4 & 0 & 25 & 0 & 4 \\
\hline 213 & CERVEZA Y MALTA & 25 & 28 & 44 & 50 & 1 \\
\hline 214 & GASEOSAS & 62 & 10 & 34 & 7 & 4 \\
\hline 22 & TABACO & 54 & 6 & 83 & 8 & 4 \\
\hline 23 & TEXTILES & 370 & 14 & 62 & 5 & 4 \\
\hline 231 & FIBRAS TEXTILES & 202 & 14 & 59 & 1 & 4 \\
\hline 2311 & Algodón & 79 & 6 & 58 & -1 & 4 \\
\hline 2312 & Lana & 33 & 18 & 65 & 12 & 4 \\
\hline 2313 & Seda & 13 & 31 & 46 & -5 & 2 \\
\hline 2314 & Fibras artificiales & 21 & 29 & 55 & -5 & 2 \\
\hline 2315 & Cáñamo & 2 & 0 & 0 & 0 & 4 \\
\hline 2316 & Lino & 3 & 0 & 100 & 0 & 4 \\
\hline 2318 & Yute y esparto & 18 & 6 & 67 & -50 & 4 \\
\hline 2319 & Otras fibras & 33 & 18 & 61 & 6 & 4 \\
\hline 232 & GÉNEROS DE PUNTO & 76 & 16 & 75 & 20 & 3 \\
\hline 239 & OTRAS & 92 & 13 & 60 & 6 & 4 \\
\hline
\end{tabular}




\begin{tabular}{|c|c|c|c|c|c|}
\hline (2) & (3) & (4) & (5) & (6) & (7) \\
\hline CALZADO Y VESTIDOS & 128 & 17 & 51 & 5 & 4 \\
\hline CALZADO & 32 & 44 & 45 & 25 & 1 \\
\hline VESTIDOS Y CONFECCIÓN & 96 & 8 & 53 & -3 & 4 \\
\hline MADERA Y CORCHO & 69 & 4 & 49 & 3 & 4 \\
\hline MADERA & 66 & 5 & 52 & 3 & 4 \\
\hline $\mathrm{CORCHO}$ & 3 & 0 & 0 & 0 & 4 \\
\hline MUEBLES & 16 & 13 & 75 & -17 & 4 \\
\hline DE MADERA & 7 & 14 & 71 & -20 & 4 \\
\hline METÁLICOS & 9 & 11 & 78 & -14 & 4 \\
\hline PAPEL & 147 & 7 & 47 & 9 & 4 \\
\hline FABRICACIÓN DE PAPEL & 80 & 10 & 41 & 7 & 4 \\
\hline FABRIC. DE ARTÍCULOS DE PAPEL & 67 & 4 & 55 & 10 & 4 \\
\hline GRAFICAS & 195 & 4 & 76 & 6 & 4 \\
\hline IMPRENTAS & 165 & 4 & 74 & 1 & 4 \\
\hline LITOGRAFÍA & 20 & 10 & 80 & 50 & 3 \\
\hline EDITORIALES & 10 & 0 & 90 & 0 & 4 \\
\hline CUERO & 34 & 32 & 38 & 15 & 1 \\
\hline CURTICIÓN Y ACABADO & 19 & 32 & 59 & 13 & 2 \\
\hline ARTICULOS DE CUERO & 15 & 33 & 13 & 38 & 1 \\
\hline CAUCHO & 85 & 40 & 36 & 6 & 2 \\
\hline NEUMÁTICOS & 26 & 23 & 56 & -27 & 2 \\
\hline CALZADO & 20 & 60 & 33 & 0 & 2 \\
\hline OTROS & 39 & 41 & 24 & 26 & 1 \\
\hline QUÍMICA & 719 & 21 & 36 & 17 & 1 \\
\hline QUIMICA INDUSTRIAL ESENCIAL & 399 & 11 & 36 & 12 & 4 \\
\hline Abonos & 28 & 11 & 30 & 16 & 3 \\
\hline Ácidos & 76 & 4 & 46 & 2 & 4 \\
\hline Alcoholes & 9 & 0 & 22 & 0 & 4 \\
\hline
\end{tabular}




\begin{tabular}{|c|c|c|c|c|c|c|}
\hline (1) & (2) & (3) & (4) & (5) & (6) & (7) \\
\hline $311 x$ & Colas & 17 & 71 & 18 & 45 & 1 \\
\hline $311 x$ & Explosivos & 13 & 15 & 11 & 25 & 3 \\
\hline $311 x$ & Gases & 56 & 4 & 32 & -3 & 4 \\
\hline $311 x$ & Insecticidas & 13 & 31 & 58 & 26 & 1 \\
\hline $311 x$ & Metales & 30 & 7 & 27 & 9 & 4 \\
\hline $311 x$ & Plásticos & 43 & 5 & 46 & 9 & 4 \\
\hline $311 x$ & Resinas & 20 & 0 & 40 & 0 & 4 \\
\hline $311 x$ & Sales & 13 & 8 & 38 & 13 & 4 \\
\hline $311 x$ & Otros & 81 & 15 & 34 & 23 & 3 \\
\hline 312 & ACEITES Y GRASAS & 60 & 18 & 27 & 9 & 2 \\
\hline 319 & DIVERSOS & 260 & 37 & 38 & 28 & 1 \\
\hline 3191 & Prod. Farmacéuticos & 59 & 5 & 55 & 5 & 4 \\
\hline 3193 & Prod. Aromáticos & 15 & 80 & 7 & -23 & 2 \\
\hline 3194 & Detergentes & 5 & 20 & 40 & -50 & 2 \\
\hline 3195 & Pinturas & 31 & 48 & 39 & 25 & 1 \\
\hline 3196 & Ceras y parafinas & 15 & 53 & 42 & 31 & 1 \\
\hline 3197 & Adhesivos & 7 & 29 & 43 & -8 & 2 \\
\hline $319 x$ & Jabones & 68 & 69 & 28 & 40 & 1 \\
\hline $319 x$ & Otros & 60 & 15 & 34 & 22 & 3 \\
\hline 32 & DERIVADOS PETROLEO Y CARBÓN & 37 & 14 & 19 & 17 & 3 \\
\hline 321 & REFINERIAS & 10 & 40 & 40 & 67 & 1 \\
\hline 322 & COQUE & 5 & 0 & 40 & 0 & 4 \\
\hline 3293 & Aglomerados de carbón & 6 & 0 & 0 & 0 & 4 \\
\hline $32 x$ & OTROS & 16 & 6 & 6 & 7 & 4 \\
\hline 33 & MINERALES NO METÁLICOS & 562 & 6 & 29 & 1 & 4 \\
\hline 331 & ARCILLA & 30 & 7 & 33 & 10 & 4 \\
\hline 332 & VIDRIO & 40 & 20 & 60 & 19 & 1 \\
\hline 333 & CERÁMICA & 19 & 11 & 47 & 20 & 3 \\
\hline 334 & CEMENTO & 194 & 8 & 40 & 2 & 4 \\
\hline 3341 & Cemento Pórtland & 92 & 10 & 47 & 5 & 4 \\
\hline 3342 & Cemento aluminoso & 6 & 17 & 60 & 50 & 3 \\
\hline 3343 & Cemento puzolánico & 5 & 0 & 75 & 0 & 4 \\
\hline 3344 & Cemento natural & 43 & 7 & 53 & -11 & 4 \\
\hline 3345 & Cales hidráulicas & 40 & 5 & 11 & 3 & 4 \\
\hline
\end{tabular}




\begin{tabular}{|c|c|c|c|c|c|c|}
\hline (1) & (2) & (3) & (4) & (5) & (6) & (7) \\
\hline $334 x$ & Otros cementos & 8 & 13 & 25 & 17 & 3 \\
\hline 339 & OTROS & 279 & 1 & 15 & -1 & 4 \\
\hline 34 & INDUSTRIAS METÁLICAS BASICAS & 276 & 8 & 51 & 10 & 4 \\
\hline 341 & HIERRO Y ACERO & 155 & 6 & 59 & 15 & 3 \\
\hline 342 & NO FERREOS & 121 & 9 & 41 & 2 & 4 \\
\hline 3421 & Aluminio & 22 & 9 & 57 & 22 & 3 \\
\hline 3422 & Cinc & 4 & 0 & 33 & 0 & 4 \\
\hline 3423 & Cobre & 13 & 0 & 0 & 0 & 4 \\
\hline 3424 & Estaño & 6 & 17 & 33 & -50 & 4 \\
\hline 3426 & Plomo & 13 & 8 & 45 & -20 & 4 \\
\hline 3429 & Otros & 63 & 11 & 44 & 7 & 4 \\
\hline 35 & PRODUCTOS METÁLICOS & 304 & 8 & 40 & -3 & 4 \\
\hline 351 & FERRETERÍA & 42 & 12 & 64 & 2 & 4 \\
\hline 352 & HERRAMIENTAS & 17 & 0 & 67 & 0 & 4 \\
\hline 353 & RECIPIENTES & 23 & 9 & 39 & 14 & 3 \\
\hline 354 & CONSTRUCCIÓN & 110 & 1 & 8 & 1 & 4 \\
\hline 357 & RECUBRIMIENTOS & 4 & 0 & 25 & 0 & 4 \\
\hline 358 & ARMAS & 2 & 0 & 100 & 0 & 4 \\
\hline 359 & OTROS & 106 & 15 & 59 & 1 & 4 \\
\hline 36 & MAQUINARIA & 110 & 15 & 61 & 3 & 4 \\
\hline 361 & MOTORES & 20 & 10 & 75 & -13 & 4 \\
\hline 362 & PARA TRABAJAR METALES & 16 & 6 & 63 & 17 & 3 \\
\hline 363 & PARA MANIPULAR FLUIDOS & 12 & 0 & 55 & 0 & 4 \\
\hline 366 & MINAS Y CONSTRUCCIÓN & 2 & 50 & 50 & 100 & 1 \\
\hline 367 & PARA INDUSTRIAS AGRÍCOLAS & 19 & 21 & 53 & -19 & 2 \\
\hline 369 & PARA OTRAS INDUSTRIAS & 41 & 20 & 59 & 8 & 2 \\
\hline 37 & MAQUINARIA ELÉCTRICA & 193 & 11 & 44 & 10 & 4 \\
\hline 371 & PRODUCCIÓN DE ELECTRICIDAD & 13 & 8 & 62 & 20 & 3 \\
\hline 372 & DISTRIBUCIÓN DE ELECTRICIDAD & 18 & 6 & 50 & 11 & 4 \\
\hline 374 & ELECTRÓNICA Y CINE & 52 & 19 & 35 & 4 & 2 \\
\hline 375 & LÁMPARAS & 13 & 8 & 42 & 14 & 3 \\
\hline 376 & PARA VEHÍCULOS & 7 & 0 & 71 & 0 & 4 \\
\hline
\end{tabular}




\begin{tabular}{|c|c|c|c|c|c|c|}
\hline (1) & (2) & (3) & (4) & (5) & (6) & (7) \\
\hline 377 & ELECTRODOMÉSTICOS & 13 & 0 & 54 & 0 & 4 \\
\hline 378 & ACUMULADORES Y PILAS & 7 & 14 & 43 & 25 & 3 \\
\hline 379 & OTROS & 41 & 17 & 49 & 14 & 3 \\
\hline $379 x$ & FRÍO INDUSTRIAL & 29 & 3 & 31 & 5 & 4 \\
\hline 38 & CONSTRUCC. MATERAL TRANSPORTE & 205 & 7 & 50 & 2 & 4 \\
\hline 381 & CONSTRUCCIONES NAVALES & 34 & 0 & 72 & 0 & 4 \\
\hline 382 & EQUIPO FERROVIARIO & 13 & 0 & 62 & 0 & 4 \\
\hline 383 & VEHÍCULOS AUTOMOVILES & 134 & 10 & 43 & 2 & 4 \\
\hline 386 & AERONAVES & 7 & 0 & 33 & 0 & 4 \\
\hline 389 & OTROS & 17 & 6 & 63 & -10 & 4 \\
\hline 39 & INDUSTRIAS FABRILES DIVERSAS & 174 & 12 & 41 & 11 & 4 \\
\hline 391 & INSTRUMENTOS CIENTIFICOS & 24 & 0 & 42 & 0 & 4 \\
\hline 392 & FOTOGRAFÍA Y ÓPTICA & 5 & 40 & 20 & 50 & 1 \\
\hline 393 & RELOJES & 6 & 0 & 40 & 0 & 4 \\
\hline 396 & INSTRUMENTOS DE MUSICA Y DISCOS & 9 & 11 & 33 & 17 & 3 \\
\hline 399 & OTROS & 130 & 14 & 43 & 12 & 4 \\
\hline 3991 & Juguetes & 5 & 0 & 100 & 0 & 4 \\
\hline 3993 & Objetos de escritorio & 15 & 13 & 29 & 20 & 3 \\
\hline 3994 & Escobas, cepillos, brochas y pinceles & 14 & 57 & 57 & 75 & 1 \\
\hline 3997 & Artículos de materias plásticas & 42 & 5 & 57 & 1 & 4 \\
\hline 3999 & Otros & 54 & 11 & 25 & 5 & 4 \\
\hline TOTAL & & 4.471 & 18 & 41 & 14 & \\
\hline
\end{tabular}
(1) C.N.A.E. $\left({ }^{*}\right)$
(2) Industrias
(3) $\mathrm{N}^{\circ}$ de expedientes
(4) Expedientes denegados (\%)
(5) Ampliaciones respecto al total (\%)
(6) Diferencia de denegación entre nuevas y ampliaciones (\%)
(7) Comportamiento estratégico $\left({ }^{\star *}\right)$
(*) Sectores industriales en función de la Clasificación Nacional de Actividades Económicas (C.N.A.E.) de 1952.
$\left({ }^{*}\right)$ Ver explicaciones en el texto y en el Cuadro 5.

Fuente: BOE, años 1940-1962. 